\title{
Influência de meios de cultura e da interação carbono-nitrogênio no crescimento e esporulação de Penicillium sclerotigenum
}

\author{
Flávia de Aquino Cutrim ${ }^{1,3}$, Sônia M.A. Oliveira ${ }^{1}$, Suzana Alencar Freire Dantas², Roberto Luiz Xavier Silva ${ }^{1}$
}

Laboratório de Patologia Pós-Colheita, Fitossanidade, DEPA/UFRPE, Recife-PE., ${ }^{2}$ IPA-Pernambuco, 50.761-000, Recife-PE., ${ }^{3}$ Bolsista CNPq. Data de chegada: 27/09/04. Aceito para publicação em: 01/07/05.

\begin{abstract}
Cutrim, F.A.; Oliveira, S.M.A., Dantas S.A.F., Silva, R.L.X. Influence of culture media and the carbon-nitrogen interaction on growth and sporulation of Penicillium sclerotigenum. Summa Phytopathologica, v. 32, n. 1, p. 85-88, 2006.

The yam green rot is a disease with high economic impact in Pernambuco state. It was carried out physiological studies involving six culture media (PDA, Oat-agar, V-8 juice, Czapeck, Carrot and Yam) on mycelial growth, sporulation and dry weight of two Penicillium sclerotigenum isolates (IB1 and IPR2). PDA and Yam media induced higher mycelial growth and higher conidium production was obtained in the Czapeck and Oat-agar for both isolates utilized. The Oat-agar media provided higher dry weight for IB1 and IPR2. It

dextrose, sucrose, starch) and nitrogen (asparagin, pepton, sodium nitrate, potassium nitrate) on development of P. Sclerotigenum. Among the nitrogen sources evaluated, sodium nitrate was the less favorable for the mycelial growth and sporulation. The sucrose $x$ pepton combination provided the best mycelial growth for both isolates. The highest conidium production was achieved using the combination of sucrose $\mathrm{x}$ potassium nitrate and sucrose $\mathrm{x}$ peptone for the isolates IB1 and IPR2, respectively.
\end{abstract} was also studied the effect of different carbon source (maltose,

Additional keywords: Green rot, Dioscorea cayennensis, postharvest, nutrition.

\section{RESUMO}

Cutrim, F.A.; Oliveira, S.M.A., Dantas S.A.F., Silva, R.L.X. Influência de meios de cultura e da interação carbono-nitrogênio no crescimento e esporulação de Penicillium sclerotigenum. Summa Phytopathologica, v. 32, n. 1, p. 85-88, 2006.

A podridão verde do inhame é uma doença de grande expressão econômica no estado de Pernambuco. Foram realizados estudos fisiológicos visando avaliar a influência de seis meios de cultura (BDA, Aveia, V-8, Czapeck, Cenoura e Inhame) sobre o crescimento micelial, esporulação e peso seco de dois isolados de Penicillium sclerotigenum (IB1 e IPR2). Os meios BDA e Inhame induziram maior crescimento micelial e, a maior produção de conídios foi obtida no Czapeck e Aveia, para ambos isolados utilizados. O meio de Aveia propiciou maior peso seco para o IB1 e IPR2. Foi estudado o efeito de diferentes combinações de fontes de carbono (maltose, dextrose, sacarose, amido) e nitrogênio (asparagina, peptona, nitrato de sódio, nitrato de potássio) sobre o desenvolvimento de $P$. sclerotigenum. O nitrato de sódio foi menos favorável ao crescimento micelial e esporulação. A combinação sacarose $\mathrm{x}$ peptona proporcionou o melhor crescimento micelial para ambos isolados. Para o IB1, a maior produção de conídios foi obtida com a sacarose $\mathrm{x}$ nitrato de potássio e para o IPR2 com a sacarose $\mathrm{x}$ peptona.

Palavras-chave adicionais: Podridão verde, Dioscorea cayennensis, pós-colheita, nutrição.

A podridão verde do inhame (Dioscorea cayennensis Lam.), causada por Penicillium sclerotigenum Yam. é considerada uma das doenças mais freqüentes nas condições de armazenamento e transporte de túberas. Embora tenha sido descrita, desde 1955, no Japão por Yamamoto et al. (10), estudos fisiológicos de $P$. sclerotigenum praticamente inexistem na literatura especializada.

O estudo fisiológico e nutricional dos fungos fornece subsídios para vários trabalhos relacionados à biologia, genética $\mathrm{e}$ bioquímica, possibilitando um melhor entendimento da relação 
patógeno-hospedeiro-ambiente (1).

A relação entre carbono e nitrogênio é muito importante para o crescimento e esporulação dos fungos; alta concentração de nitrogênio reprime a esporulação e está diretamente ligada a concentração de carbono (2). A concentração mínima de nutrientes que permite o crescimento micelial é, muitas vezes, insuficiente para produzir esporos, ou seja, geralmente a condição nutricional ótima para o crescimento micelial não é necessariamente a melhor para a produção de esporos e freqüentemente inibe a reprodução (9).

Com base nesses argumentos, e pela necessidade de se conhecer as exigências nutricionais de $P$. sclerotigenum, causador de importante doença pós-colheita em túberas de inhame, avaliou-se diferentes meios de cultura e combinações de carbono e nitrogênio que proporcionassem o melhor desenvolvimento deste fitopatógeno.

Os isolados foram obtidos a partir de túberas de inhame (Dioscorea cayennensis Lam.) cv. da Costa, apresentando sintoma característico de podridão verde provenientes da Paraíba (IPB), Paraná (IPR1; IPR2) e Pernambuco (IAL; IBI; IB2; IBG; IG). Os fragmentos foram desinfestados, plaqueados em meio batata-dextrose-ágar (BDA) e incubados a temperatura de $25 \pm 2$ ${ }^{0} \mathrm{C}$. Após o crescimento do fungo transferiu-se discos contendo estruturas do $P$. sclerotigenum para tubos de ensaio com meio BDA.

Os isolados de P. sclerotigenum obtidos foram testados quanto á patogenicidade, por meio de inoculação com discos de meio contendo as estruturas vegetativas e reprodutivas do fungo nas túberas de inhame sadias e previamente desinfestadas em hipoclorito de sódio $(1,5 \%)$, feridas, e que após a inoculação foram mantidas em câmara úmida por $48 \mathrm{~h}$. A avaliação foi realizada 10 dias após a inoculação pela medição do diâmetro e profundidade da lesão, com auxílio da régua milimetrada. O delineamento experimental empregado foi inteiramente casualizado com cinco repetições e as médias foram comparadas pelo teste de Tukey a $5 \%$ de probabilidade, utilizando o Programa SANEST.

$\mathrm{O}$ estudo sobre a influência de diferentes meios de cultivo, líquido e sólido, sobre o crescimento micelial e esporulação foi realizado com dois isolados de $P$. sclerotigenum mais agressivos. Para determinação do crescimento micelial e esporulação foram utilizados os meios agarizados BDA, Cenoura, V-8, Aveia, Czapeck, segundo Menezes \& Silva-Hanlin (5), e inhame (200 g de inhame; $10 \mathrm{~g}$ de dextrose; $20 \mathrm{~g}$ de ágar). Para avaliação do peso seco foram utilizados os meios acima mencionados sem adição de ágar. A avaliação do crescimento micelial consistiu na medição diária do diâmetro das colônias com uma régua milimetrada e a esporulação por meio de leitura em câmara de Neubauer (5). O peso seco foi obtido através da filtração da cultura, e seguido da secagem do filtrado em estufa a $80^{\circ} \mathrm{C}$ por 24 horas. $\mathrm{O}$ delineamento experimental empregado foi inteiramente casualizado, em arranjo fatorial com cinco repetições por tratamento, e as médias foram comparadas pelo teste de Tukey a $5 \%$ de probabilidade utilizando-se o Programa SANEST.

Também, para identificação das melhores fontes de carbono e nitrogênio foram utilizadas combinações de quatro fontes de carbono (C): maltose, dextrose, sacarose e amido com quatro de nitrogênio $(\mathrm{N})$, sendo duas orgânicas: asparagina e peptona e duas inorgânicas: nitrato de potássio e nitrato de sódio, na pro- porção 10:1, conforme o peso molecular, tendo como meio basal o de Lilly \& Barnett (4). A avaliação do crescimento micelial e esporulação foi feita de acordo com a metodologia anteriormente descrita. O delineamento experimental utilizado foi inteiramente casualizado, em arranjo fatorial, com cinco repetições, e as médias foram comparadas pelo teste de Tukey (5\% de probabilidade). Para efeito de análise estatística dos dados foi utilizado o programa SANEST.

Após a realização de cortes feitos no local de infecção foi possível visualizar uma área necrótica, de coloração marromclara, tomando grande parte da polpa, sintomas estes semelhantes aos observados por Moura (7), verificando-se que todos os isolados de $P$. sclerotigenum testados foram patogênicos quando inoculados em túberas de inhame sadias, sendo que o IB1 e IPR2 foram mais agressivos.

Em relação aos meios de cultura testados, pode-se observar na Figura 1 que, de um modo geral, os isolados apresentaram comportamento ao que concernem as variáveis testadas. Os
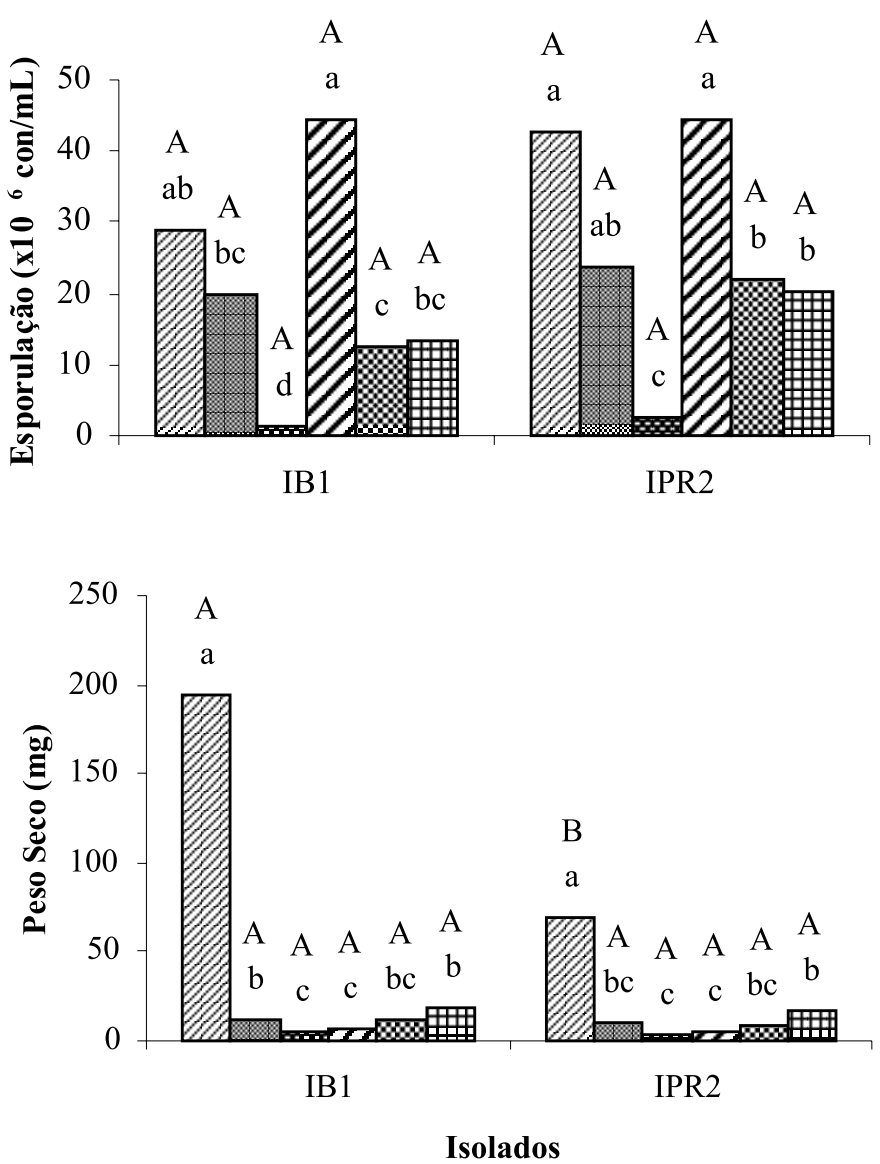

Figura 1. Crescimento micelial, esporulação e peso seco de dois isolados de Penicillium sclerotigenum (IB1 e IPR2), agente causal da podridão verde do inhame, em diferentes meios de cultura, aos sete dias de incubação.

Médias seguidas da mesma letra, maiúscula entre as categorias e minúscula dentro das categorias, não diferem entre si pelo teste de Tukey ao nível de $5 \%$ de probabilidade. Médias de cinco repetições. 
substratos BDA e Inhame induziram maior crescimento micelial para ambos isolados testados, enquanto os meios Czapeck e Aveia mostraram-se mais adequados para esporulação. Muitos fungos utilizam melhores os meios naturais ou semi-sintéticos para o seu desenvolvimento, os quais fornecem determinadas substâncias que funcionam como estimuladores de crescimento e reprodução, o que torna esses meios mais eficientes do que os

Tabela 1. Influência de fontes de carbono e nitrogênio sobre o crescimento micelial (mm) e esporulação de dois isolados de Penicillium sclerotigenum, agente causal da podridão verde do inhame, após sete dias de incubação

\begin{tabular}{|c|c|c|c|c|c|}
\hline \multirow[t]{2}{*}{ Isolado } & \multirow{2}{*}{$\begin{array}{l}\text { Fonte de } \\
\text { Carbono }\end{array}$} & \multicolumn{4}{|c|}{ Fonte de Nitrogênio } \\
\hline & & $\mathrm{NNa}$ & NK & Asp & Pep \\
\hline \multicolumn{6}{|c|}{ Crescimento micelial (mm) } \\
\hline \multirow[t]{4}{*}{ IB1 } & Dextrose & 3,41 a $D^{*}$ & $4,47 \mathrm{~b}$ B & 4,37 b C & $6,70 \mathrm{~b} \mathrm{~A}$ \\
\hline & Maltose & 0,92 b D & 4,66 a B & 4,42 a C & $5,38 \mathrm{~d} \mathrm{~A}$ \\
\hline & Amido & 0,00 c D & $4,52 \mathrm{c} \mathrm{B}$ & 4,35 c C & $5,58 \mathrm{c} \mathrm{A}$ \\
\hline & Sacarose & $0,00 \mathrm{c} \mathrm{D}$ & $4,60 \mathrm{~b} \mathrm{~B}$ & $4,25 \mathrm{~d} \mathrm{C}$ & 6,72 a $A$ \\
\hline \multirow[t]{4}{*}{ IPR2 } & Dextrose & 2,12 a $\mathrm{D}$ & 3,95 с C & $3,98 \mathrm{~d} B$ & $6,16 \mathrm{~b} \mathrm{~A}$ \\
\hline & Maltose & $0,65 \mathrm{~b} \mathrm{D}$ & $3,80 \mathrm{~d} \mathrm{C}$ & 4,07 c B & $5,33 \mathrm{~d} A$ \\
\hline & Amido & 0,00 c D & 4,16 b C & $4,21 \mathrm{~b} \mathrm{~B}$ & $5,49 \mathrm{c} \mathrm{A}$ \\
\hline & Sacarose & $0,00 \mathrm{c} \mathrm{D}$ & 4,47 a C & 4,66 a $B$ & 7,30 a $\mathrm{A}$ \\
\hline
\end{tabular}

Esporulação (x 106 conídios/mL)

$\begin{array}{cccccc}\text { IB1 } & \text { Dextrose } & 0,76 \text { a D* } & 7,26 \text { c B } & 5,61 \text { c C } & 12,88 \text { b A } \\ \text { Maltose } & 0,14 \text { b D } & 7,43 \text { b A } & 6,12 \text { b B } & 3,13 \text { c C } \\ \text { Amido } & 0,00 \text { c D } & 6,09 \text { c B } & 4,62 \text { a A } & 1,88 \text { d C } \\ \text { Sacarose } & 0,00 \text { c D } & 15,67 \text { a A } & 5,25 \text { d C } & 15,61 \text { a B }\end{array}$

$\begin{array}{cccccc}\text { IPR2 } & \text { Dextrose } & 0,14 \text { a D } & 7,35 \text { c C } & 10,20 \text { b A } & 8,20 \text { b B } \\ \text { Maltose } & 0,00 \text { b D } & 4,39 \text { d C } & 7,45 \text { d B } & 8,03 \text { c A } \\ \text { Amido } & 0,00 \text { b D } & 9,14 \text { b B } & 9,60 \text { c A } & 5,10 \text { d C } \\ \text { Sacarose } & 0200 \text { b D } & 16,16 \text { a C } & 17,11 \text { a B } & 46,72 \text { a A }\end{array}$

\footnotetext{
* Médias seguidas da mesma letra, minúsculas na vertical e maiúsculas na horizontal, não diferem entre si pelo teste de Tukey $(\mathrm{P}=0,05)$ dentro de cada isolado. Médias de cinco repetições/combinação. Dados transformados em $\sqrt{\mathrm{x}+3}$ para esporulação.

$\mathrm{NNa}=$ Nitrato de sódio $; \mathrm{NK}=$ Nitrato de potássio $;$ Asp = Asparagina; Pep $=$ Peptona.
}

sintéticos $(3 ; 4)$. O maior peso seco foi obtido no meio de Aveia (Figura 1) para ambos isolados de P. sclerotigenum. No estudo de nutrição de fungos, a melhor variável de avaliação do crescimento micelial é através da determinação do peso seco, isso porque alguns fungos crescem muito bem em determinados substratos, porém não utilizam eficientemente os nutrientes presentes, resultando na produção de micélio mais leve (8).

Os resultados da interação C x N sobre o crescimento micelial dos dois isolados de $P$. sclerotigenum estão representados na Tabela 1, verificando-se que houve efeito significativo das diferentes combinações de $\mathrm{C}$ e $\mathrm{N}$ no crescimento micelial dos isolados IB1 e IPR2. A melhor resposta induzida pela peptona era esperada, uma vez que a disponibilidade do nitrogênio nas fontes orgânicas é bem maior que nas inorgânicas (2). Segundo Assis et al. (1), o estado nutricional do fungo afeta o crescimento e germinação de esporos. O nitrato de sódio, independente da fonte de carbono foi considerado a menos favorável ao desenvolvimento de $P$. sclerotigenum, sendo, portanto, inviável para ser utilizada. A sacarose, como fonte de carbono, combinada com nitrato de potássio e peptona, respectivamente, para o IB1 e IPR2, ofereceu maior esporulação. A fonte de C mais adequada para suprir as exigências nutricionais de $P$. sclerotigenum foi à sacarose. Segundo Morre-Landercker (6), esse fato pode ter ocorrido devido a fatores genéticos ou a condições ambientais, pois sabe-se que a sacarose é uma fonte complexa de açúcar que exige do fungo um gasto adicional de energia na síntese de enzimas para degradação dos mesmos (6).

De modo geral, os meios de cultura BDA e inhame favoreceram o crescimento micelial do fitopatógeno. $\mathrm{O}$ maior peso seco foi verificado quando cultivado em aveia e a esporulação nos meios Czapeck e aveia. As fontes de peptona e sacarose proporcionaram maior desenvolvimento de $P$. sclerotigenum.

\section{REFERÊNCIAS BIBLIOGRÁFICAS}

1. Assis, T.C.; Menezes, M.; Andrade, D.E.G.T.; Coelho, R.S.B.; Oliveira, S.M.A. Estudo comparativo de isolados de Colletotrichum gloeosporioides quanto ao efeito da nutrição de carboidratos no crescimento, esporulação e patogenicidade em frutos de três variedades de mangueira. Summa Phytopathologica, Jaboticabal, v.27, n.2, p.208-212, 2001.

2. Griffin, D.H. Fungal physiology. 2 ed. New York: John Wiley, 1994. 428p.

3. Hawker, L.E. The physiology of reproduction in fungi. London: Cambridge University Press, 1957. 127p.

4. Lilly, V.G.; Barnett, H.L. Physiology of the fungi. New York: McGraw-Hill, 1951.464p.

5. Menezes, M.; Silva-Hanlin. D.M.W. Guia prático para fungos fitopatogênicos. Recife: Imprensa Universitária da UFRPE, 1997. 277p.

6. Morre-Landercker, E. Fundamentals of the fungi. New Jersey: Prentice Hall, 1972. 482p.

7. Moura, R.M. Doenças do inhame. In: Kimati, H.; Amorim, L.; Bergamin Filho, A.; Camargo, L.E.A.; Rezende, J.A.M. Manual de fitopatologia: doenças das plantas cultivadas. 3 ed. São Paulo: Agronômica Ceres, 1997. v.2, p.463-471. 
8. Terao, D.; Oliveira, S.M.A.; Tavares, S.C.C.H.; Laranjeira, D. Efecto de la nutrición sobre desarrollo vegetativo y reproductivo del agente de la malformación floral y vegetativa del mango. Boletín Micológico, Valparaíso, v.16, p.57-63, 2001.

9. Véras, S.M.; Gasparroto, L.; Menezes, M. Variabilidade fisiomorfológica de Colletotrichum guaranicola em diferentes substratos. Arquivos de Biologia e Tecnologia, Curitiba, v.40, n.2, p.297-305, 1997.

10. Yamamoto, W.; Yoshitani, K.; Maeda, M. Studies on the Penicillium and Fusarium rots of Chinese yam and their control. The Science Reporter of the Hyogo University of Agriculture, Sasayama-cho, v.2, n.1, p.69-79, 1955. 